\title{
MOSAICOS EPISTOLARES NA MPB
}

\author{
Luciana M. do Nascimento (UFAC) \\ luciana@ufac.br \\ João Gabriel Lopes de Brito (UFAC)
}

\section{Introdução}

Podemos afirmar que as letras de música constituem textos poéticos, se as lermos sob a perspectiva dos estudos sobre as funções da linguagem de Roman Jakobson ou sob a ótica dos estudos de Octavio Paz sobre a linguagem da poesia, em especial, seu famoso ensaio "poesia e poema". Neste ensaio, o crítico e poeta mexicano nos ensina que poesia é essência, sendo que esta não se realiza apenas num poema canônico, mas em muitos outros espaços, como na música, na pintura, na prosa etc. Podemos observar que as letras de música, sem dúvida, são constituídas de recursos estilísticos que cumprem a função de despertar fantasias e emoções no ouvinte e tais recursos poéticos se fazem presentes no modo de organização do discurso. Como bem afirma Eneida Maria de Souza:

(...) Não causa mais espanto o fato de a literatura brasileira e, especificamente, a poesia brasileira, conceber a música popular como parte integrante de seu cânone (...). Em decorrência da abertura nos estudos semiológicos e culturais, respectivamente a partir dos anos 1960 e 1980, a hegemonia da abordagem literária - voltada para a exclusividade de textos representativos da literatura - começa a ceder terreno para o caráter interdisciplinar e pluralista das manifestações artísticas. (SOUZA, 2002, p. 147)

Tradicionalmente, o discurso lítero-musical tem sido estudado pelos departamentos de literatura das universidades ou por críticos literários que também são escritores (poetas, romancistas ou dramaturgos). Há diversos autores que escreveram importantes textos sobre a música popular brasileira e fizeram relevantes reflexões sobre a música e sua vinculação à poesia, podemos cita alguns deles, a saber: Affonso Romano de Sant'Anna (1986), Augusto de Campos (1968), José Miguel Wisnik (1996), dentre outros. Affonso Romano de Sant'Anna:

Os textos de música popular brasileira passaram a ser estudados rotineiramente nos cursos de literatura de nossas Faculdades de Letras. Isto 
se deve a uma expansão da área de interesse dos professores e alunos, e a uma confluência entre música e poesia que cada vez mais se acentua desde que poetas como Vinícius de Morais voltaram-se com força total para a música popular e que autores como Caetano e Chico se impregnaram de literatura (SANT'ANNA, 1986, p. 99).

Muitos autores realizaram as duas práticas simultaneamente, a saber: o fazer literário e a composição musical. Um exemplo modelar dessa prática foi o caso do letrista, compositor e poeta Vinícius de Moraes. Ele iniciou seu trabalho artístico com a canção "Loura ou morena" (1932), um ano antes da Publicação de seu primeiro livro de poesias, "Caminhos para a distância" (SANT'ANNA, 1986, p. 214).

Sendo Vinícius também músico, o seu trabalho com a literatura aliou as duas práticas, tendo em vista a grande quantidade tanto de letras de música quanto de poesias publicadas, tendo frequentado tanto os círculos de poetas quanto os de músicos. É consenso nos meios literários que a origem de trabalho de Vinícius está na literatura, como atestam as palavras de Affonso Romano de Sant'Anna: "a análise global da obra de Vinícius de Moraes talvez pertença mais aos estudos literários propriamente ditos, porque ele está comprometido, na origem com esses valores culturais elitistas e tradicionais". (SANT'ANNA, op. cit., p. 215)

Será objeto de nosso estudo, a linguagem poética aliada aos estudos das técnicas de composição e estruturação utilizadas pelos músicos (Vinícius de Moraes e Djavan), além de verificarmos também as relações intertextuais presentes nas canções "Samba em prelúdio", de Vinícius de Moraes e Baden Powell e "A Carta”, de Djavan.

\section{Gênero carta}

De acordo com Bakthin, em todas as esferas de comunicação utilizamos um gênero específico para determinada situação de uso da língua, sendo a enunciação um produto da inter-relação social:

Todas as esferas da atividade humana, por mais variadas que sejam, estão sempre relacionadas com a utilização da língua. Não é de se surpreender que o caráter e os modos dessa utilização sejam tão variados como as próprias esferas da atividade humana, o que não contradiz a unidade nacional de uma língua. (BAKTHIN, 1995, p. 248) 
A música como forma de comunicação artística se apropria de gêneros típicos da comunicação cotidiana, como é o caso do gênero carta, presente na canção "Samba em prelúdio", de Vinícius de Moraes e Baden Powell, composta em 1962.

Na canção "Samba em prelúdio", de Vinícius de Moraes, com a parceria de Baden Powell, sobressai um elemento de grande importância, a começar pelo título "Samba" e "Prelúdio", como veremos a seguir. $\mathrm{O}$ samba é um gênero musical de raízes africanas, que remonta ao séc. XVII, na Bahia onde escravos originários de Angola e do Congo aportaram, difundindo suas rodas de Semba, cuja tradução seria umbigada. (GONÇALVES; COSTA, 2000). O Samba sofreu um processo de urbanização gradual, mas já apresentando como traços característicos, a marcação binária e um ritmo fortemente sincopado (GROVE, 1994).

Como composição feita em plena efervescência da Bossa Nova, "Samba em Prelúdio" apresenta-se como um samba em tom menor; já o prelúdio constitui um movimento musical destinado a preceder uma obra maior ou grupo de peças. Os prelúdios evoluíram a partir de improvisações feitas pelos instrumentistas para testar a afinação, o toque e o timbre de seus instrumentos. (GROVE, 1994). No prelúdio de "Samba em Prelúdio", pode-se observar uma espécie de carta-confissão endereçada à amada. Tal gênero textual corresponde um meio útil para manter a comunicação. Mesmo à distância, a carta proporciona a interação entre duas ou mais pessoas, pois pode ser escrita ou lida colaborativamente, sendo que de modo geral, é enviada de um indivíduo para outro. É uma forma de comunicação muito presente nas obras literárias, não só nos próprios romances epistolares, ou seja, naqueles escritos sob a forma de cartas, gênero que floresceu no século XVIII, mas também perdurando com alguns intertextos, nos romances do século XIX. Lembremos alguns exemplos, tais como "A Moreninha", de Joaquim Manuel de Macedo ou "Amor de Perdição", de Camilo Castelo Branco, sendo esse dois romances de fins do século XIX, que apresentam como Leit Motiv, a escrita de uma carta. Ressalte-se também a presença da epistolografia na Bíblia, com a exortação dos povos ao Cristianismo. 
Pode-se dividir a canção-poema "Samba em Prelúdio" em duas partes: "prelúdio", parte lírica, de Vinícius de Moraes e o "samba", a segunda parte, que foi composta por Baden Powell.

No texto, de modo geral, predomina um sujeito poético que se expõe sem medidas, manifestando um amor-adoração, típico das cantigas dos trovadores medievais. No tocante amor medievo, Alexandre Pinheiro Torres atesta que na manifestação lírica nesse período, o amor surge como o grande e sempre eterno tema da poesia trovadoresca, o qual se manifestou na sociedade feudalista e tornou-se conhecido ainda pela expressão "amor cortês". É por meio do "amor cortês" que o trovador poetiza um atroz sofrimento de amor, as famosas "coitas de amor" (penas de amor). (TORRES, 1997, p. 5-7). A tradicional e feliz combinação entre música e poesia foi popularizada pelas cantigas trovadorescas. Nesse cenário, trovadores e menestréis eram sinônimos de poetas. Com relação aos trovadores, o crítico português afirma que nos tempos medievos, o trovador utilizava de técnicas musicais bem sofisticadas, pois os poemas eram escritos sempre com certo rigor no que diz respeito às questões métricas e rítmicas, não havendo, dessa forma, espaço para a liberdade nas composições.

Vinícius nos fala de um amor de caráter submisso para com sua amada, tornando-se passivo e refém do sentimento que possui. Nesse caso, diferentemente das cantigas medievais, encontramos um homem sofredor que apesar de atrelar sua existência à amada, também compara a não concretização desse amor a algumas ações impossíveis de ocorrer no plano material, o que pode ser observado a partir de expressões, como "chama sem luz", por exemplo.

Essa carta-confissão tem suas origens na própria criação da música, pois, inicialmente, Vinícius e Baden possuíam apenas a música e, segundo narra o filho de Powell, ao final de uma noite regada à whisky, o poetinha, escreveu rapidamente um poema em uma folha de papel e estava pronto o "Samba em Prelúdio". Conforme narra o filho de Baden Powell, assim surgiu a composição de "Samba em prelúdio":

Toda música tem uma história, era o que o Baden costumava dizer sobre sua parceria com Vinicius de Moraes. Dentre as várias histórias que ouvi ele contar em shows e em casa, tem uma que considero especial 


\title{
DePARTAMENTO DE LETRAS
}

- sobre uma das mais belas e conhecidas canções de Baden e Vinícius. Resolvi manter a versão original do fato tal como o papai contava. ${ }^{14}$

\section{Prelúdio}

Eu sem você

Não tenho porque

Porque sem você

Não sei nem chorar

Sou chama sem luz

Jardim sem luar

Luar sem amor

Amor sem se dar.

Eu sem você

Sou só desamor

Um barco sem mar

Um campo sem flor

Tristeza que vai

Tristeza que vem

Sem você, meu amor, eu não sou ninguém.

\section{Samba}

\author{
Ai, que saudade \\ Que vontade de ver renascer nossa vida \\ Volta querida (querido) \\ Os teus braços precisam dos meus. \\ Meus braços precisam dos teus. \\ Estou tão sozinho (sozinha) \\ Tenho os olhos cansados de olhar para o além \\ Vem ver a vida \\ Sem você, meu amor, eu não sou ninguém.
}

Podemos notar ao logo do "Prelúdio", o predomínio do ilógico no amor, ao observarmos os pares: "chama sem luz"; "barco sem mar"; "campo sem flor". Tais pares expressam diversas situações, a saber: a analogia do sujeito poético aos elementos da natureza, a ausência da pessoa amada, que metaforicamente é expressa como elemento de aniquilação da beleza de tal natureza, sendo que o sujeito desejante conclui seu prelúdio com a total anulação de si: "Sem você, meu amor, eu não sou ninguém”.

\footnotetext{
${ }^{14}$ Disponível em: http://meuespasmo.blogspot.com/2009/11/boa-historia-de-samba-empreludio.htm. Acesso em: 11/12/2010)
} 
No "samba", o sujeito poético prossegue clamando pela ausência da pessoa amada, porém, diferentemente do "prelúdio", o eu lírico clama pela volta dessa pessoa, num movimento de memória: "Que vontade de ver renascer nossa vida / Volta querida (querido) / Os teus braços precisam dos meus. / Meus braços precisam dos teus", mostrando que o encontro amoroso pode se concretizar, afastando-se da confissão do "prelúdio" e ao final, o sujeito poético conclama à pessoa amada a "ver a vida", utilizando-se da possibilidade de anulação de si como estratégia de convencimento dirigida àquela: "Sem você, meu amor, eu não sou ninguém."

\subsection{Alguns elementos da estruturação musical}

\section{SambaemPrelúdio}

Intro: Am7

Am7 $\quad$ E7

Eu sem você não tenho porque
A7
Dm7

Porque sem você não sei nem chorar

Bm5-/7 $\quad$ E7 $\quad$ Am7

Sou chama sem luz, jardim sem luar

B7 $\quad$ E7

Luar sem amor, amor sem se dar

Am7 $\quad$ E7

E eu sem você sou só desamor

$\begin{array}{ll}\text { A7 } & \text { Dm7 }\end{array}$

Um barco sem mar, um campo sem flor

Bm5-/7 E7 Am7

Tristeza que vai, tristeza que vem

$\begin{array}{llll}\text { B7 } & \text { E7 } & \text { Am7 } & \text { E7 }\end{array}$

Sem você, meu amor, eu não sou ninguém

$\begin{array}{llll}\text { Am7 } & \text { E7 } & \text { A7 } & \text { Dm7 }\end{array}$

Ai que saudade, que vontade de ver renascer nossa vida

Bm5-/7 E7 Am7 B7

Vol ... ta querida, os teus braços precisam dos meus E7

Meus abraços precisam dos teus
Am7
E7
A7
Dm7

Estou tão sozinho, tenho os olhos cansados de olhar para o além

Bm5-/7 E7 Am7

Vem ver a vida

Sem você, meu amor, eu não sou ninguém 
Ritmo melódico: Melodia, ritmo e harmonia são considerados os três elementos fundamentais da música; encará-los como independentes, seria uma simplificação excessiva. O ritmo é componente importante da própria melodia não apenas porque cada nota tem uma duração, mas também porque a articulação rítmica numa escala mais ampla lhe dá forma e vitalidade; por outro lado, a harmonia geralmente desempenha papel essencial, ao menos na música ocidental, na determinação do contorno e direção de uma linha melódica, cujas implicações harmônicas podem, por sua vez, dar vida á melodia.

Ritmo: A subdivisão de um lapso de tempo em seções perceptíveis; o agrupamento de sons musicais, principalmente por meio de duração e ênfase. Com a melodia e Harmonia o ritmo é um dos três elementos básicos da música. (Grove).

Segundo Schafer, ritmo é algo mais orgânico e sensorial, conforme explica em seu livro "O ouvido Pensante": "O ritmo é a direção. O ritmo diz: "eu estou aqui e quero ir para lá". Ainda de acordo com o autor, originalmente Ritmo e rio estavam etimologicamente ligados, sugerindo mais o movimento de um trecho do que sua divisão.

No caso da Música "Samba em Prelúdio", temos este "fluir" na forma de samba, que como foi dito anteriormente, trata-se de uma divisão temporal binária e sincopada.

Harmonia: É a combinação de notas soando simultaneamente, para produzir acordes e sua utilização sucessiva para produzir progressões de acordes. (GROVE, 1994). Juntamente com a harmonia e como consequência desta, aparece o que chamamos de tonalidade. De acordo com Grove, o termo designa a série de relações entre notas, em que uma em particular, a "tônica", é central. O termo se aplica mais comumente ao sistema utilizado na música erudita ocidental, do séc. XVII ao XX. Nesse sistema, diz-se que a música tem uma determinada tonalidade, quando as notas predominantemente utilizadas formam uma escala maior ou menor, a tonalidade é a da tônica ou nota final dessa escala, e é maior ou menor segundo as alturas das notas que a escala abrange. (GROVE, 1994) 


\section{Djavan e "A Carta"}

Seguindo o exemplo de Vinícius, temos um autor como Djavan, sendo este pertencente a um grupo da MPB mais recente, que por seu turno, pode ser considerado como Poeta, compositor e músico, sem prejuízo do discurso poético ou da estruturação musical.

A canção "A Carta", de Djavan, foi composta em 1998 em parceria com Gabriel, o Pensador e tem como eixo temático a junção e a dinâmica de gêneros distintos entre si na cena poética. Fazemos aqui um parêntese, ao nos remetermos, a título de exemplo, à cartaensaio, de E.M. Melo e Castro. (Apud. Galvão e GOTLIB, 2000). MELO e CASTRO nos fornece bons elementos para o estudo da dinâmica comunicativa da carta e como texto sob a forma de carta pode se diluir em outros gêneros textuais, tornando-se um outro texto que já não é mais a carta nem o ensaio. A carta constitui um tipo específico de interação, um processo de comunicação com suas particularidades, sendo, portanto, diferente, por exemplo, do telegrama, do telefonema, do fax, do e-mail, da conversação face a face.

Na canção de Djavan, não só o título nos fornece indícios do gênero epistolar, como também a estrutura das notícias que vão sendo dadas passo a passo, para um possível interlocutor distante. Primeiramente, a música se abre com os conselhos de bem viver de um sujeito poético, que se põe a ler uma carta para o seu possível interlocutor. Inclusive, ressalte-se que a citação da "carta" é feita entre aspas, o que nos mostra a presença da citação, ainda que de caráter ficcional do discurso de outrem como processo intertextual. Tal citação cumpre a função de conferir relevância às notícias enviadas do Brasil ao sujeito poético, sendo que nesse momento, a música modifica seu arranjo melódico para um tom mais próximo da fala, bem como se aproxima da estrutura do Rap, com todos os seus elementos de contestação. 


\subsection{Elementos da estruturação musical}

\section{ACarta}

$\begin{array}{cccc}\text { C\#m7 } & \text { D\#m7 } & \text { E7M } & \text { D\#m7 } \\ \text { Não vá levar tudo tão a sério } & \\ \text { C\#m7 } & \text { D\#m7 } & \text { E7M } & \text { D\#m7 }\end{array}$

Sentindo que dá, deixa correr

$\begin{array}{llll}\text { C\#m7 } & \text { D\#m7 } & \text { E7M } & \text { D\#m7 }\end{array}$

Se souber confiar no seu critério

C\#m7 D\#m7 E7M D\#m7 Nada a temer

C\#m7 $\quad$ D\#m7 $\quad$ E7M D\#m7

Não vá levar tudo tão na boa

$\begin{array}{llll}\text { C\#m7 } & \text { D\#m7 } & \text { E7M D\#m7 }\end{array}$

Brigue para obter o melhor

$\begin{array}{llll}\text { C\#m7 } & \text { D\#m7 } & \text { E7M } & \text { D\#m7 }\end{array}$

Se errar por amor Deus abençoa

C\#m7

Seja você

A7(9) G\#m7 C\#7(9)

No que sua crença vacilou

A7(9) $\quad$ G\#m7 $\quad$ C\#7(9)

A flor da dúvida se abriu

F\#m7 $\quad$ B7(9) $\quad$ G\#m7

Vou ler a carta que o Biel mandou C\#7(9)

Pra você, lá do Brasil:

A7(9)

OBS: Trecho cantado em (RAP)

Eles me disseram tanta asneira, disseram só besteira feito todo mundo diz

Eles me disseram que a coleira e um prato de ração era tudo que um cão sempre quis

Eles me trouxeram a ratoeira como um queijo de primeira que me, que me pegou pelo nariz

Me deram uma gaiola como casa, amarraram minhas asas

e disseram para eu ser feliz

Mas como eu posso ser feliz num poleiro?

Como eu posso ser feliz sem pular?

Mas como eu posso ser feliz num viveiro?

Se ninguém pode ser feliz sem voar?

Ah, segurei o meu pranto para transformar em canto

E para o meu espanto minha voz desfez os nós

Que me apertavam tanto

E já sem a corda no pescoço, sem a grade na janela

E sem o peso das algemas na mão

Eu encontrei a chave dessa cela 
Devorei o meu problema e engoli a solução

Ah, se todo o mundo pudesse saber

Como é fácil viver fora, fora dessa prisão

E descobrisse que a tristeza tem fim

E a felicidade pode ser simples como um aperto de mão

Entendeu?

\section{C\#m7 D\#m7 E7M}

É esse o vírus que eu sugiro que você contraia

D\#m7 C\#m7

Na procura pela cura da loucura

D\#m7 E7M $\quad$ D\#m7

Quem tiver cabeça dura vai morrer na praia

E7M D\#m7 C\#m7

É esse o vírus que eu sugiro que você contraia

D\#m7 E7M

Na procura pela cura da loucura

D\#m7 C\#m7 D\#m7

Quem tiver cabeça dura vai morrer na praia

\section{Considerações finais}

Ao levantarmos os elementos textuais bem como àqueles relacionados à estruturação musical, foi possível perceber a relação entre música e poesia bem como a absorção de outros gêneros musicais e textuais em um mesmo texto musical, o que constitui farto material para o professor de Língua Portuguesa e Literatura explorar na sala de aula, na perspectiva do estudo do texto baseado na teoria dos gêneros discursivos.

\section{REFERÊNCIAS BIBLIOGRÁFICAS}

BAKHTIN, Mikhail. Estética da criação verbal. São Paulo: Martins Fontes, 1995.

CAMPOS, Augusto de. Balanço da bossa e outras bossas. 5. ed. São Paulo: Perspectiva, 1968.

Dicionário Grove de Músical Edição concisa preparada por Stanley Sadie e Alison Latham. Trad. Eduardo Francisco Alves. Rio de Janeiro: Jorge Zahar, 1994. 
GONÇALVES, Guilherme; COSTA, Mestre Odilon. O batuque carioca. As baterias das escolas de Samba do Rio de Janeiro.

NORTON, W.W. A History of Western Music. 2. ed. Trad. Ana Luísa Faria. Janeiro de 2001.

PAZ, Octavio. A dupla chama, amor e erotismo. São Paulo: Sciliano, 1994.

PROENÇA FILHO, Domício. A linguagem literária. São Paulo: Ática, 1988.

Revista Livro Aberto. Música e literatura. São Paulo: Cone Sul, n. 7 , março-maio, p. 08-16, 1998.

SANT'ANNA, Affonso R. de. Música popular e moderna poesia brasileira. 3. ed. Petrópolis: Vozes, 1978.

SCHAFER, Murray R. O ouvido pensante. Trad. Maria Trench de O. Fonterrada; Magda R. Gomes da Silva, Maria Lúcia Pascoal. São Paulo: UNESP, 1991.

SIQUEIRA JÚNIOR. Carlos Leoni R. Letra, música e outras conversas. Rio de Janeiro: Gryphus, 1995.

SOUZA, Eneida Maria de. Crítica Cult. Belo Horizonte: UFMG, 2002 .

TATIT, Luiz. $O$ cancionista: composição de canções no Brasil. São Paulo: Edusp, 1996.

TORRES, Alexandre Pinheiro. Antologia da poesia trovadoresca galego- portuguesa. Porto: Lello \& Irmão, 1977.

WISNIK, José Miguel. O som e o sentido - uma outra história das músicas. São Paulo: Cia. das Letras, 1999.

MELO E CASTRO, E. M. Carta-ensaio. In: GALVÃO, Walnice Nogueira e GOTLIB, Nádia. Prezado senhor, prezada senhora: estudos sobre cartas. São Paulo: Cia. das Letras, 2000.

http://meuespasmo.blogspot.com/2009/11/boa-historia-de-sambaem-preludio.htm. Acesso em: 11/12/2010. 